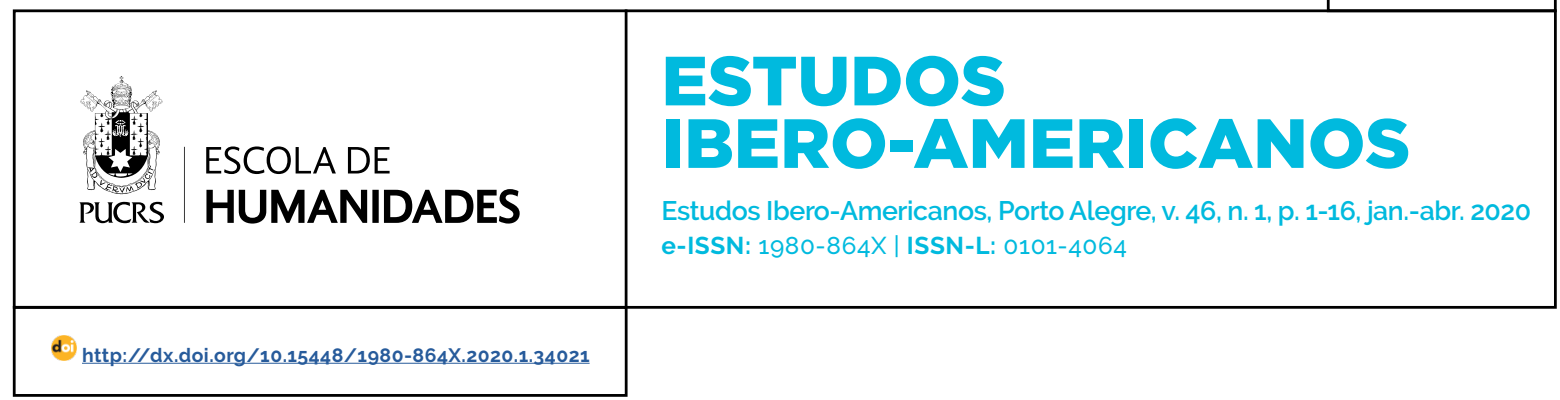

SEÇÃO: DOSSIÊ

\title{
A agricultura e floresta dos alemães no Brasil: mobilidade, conhecimentos e transfers no Urwald (século XIX)
}

\author{
La agricultura y el bosque de los alemanes en Brasil: movilidad, conocimientos y \\ transfers en el Urwald (siglo XIX) \\ The agriculture and forests of the Germans in Brazil: mobility, knowledge and transfers \\ in the Urwald (19th century)
}

\author{
Eduardo Relly ${ }^{1}$ \\ orcid.org/0000-0001-5196-7332 \\ erelly@hotmail.com
}

Recebido em: 7 mai. 2019.

Aprovado em: 26 set. 2019.

Publicado em: 28 abr. 2020.

\section{(c) (1)}

Artigo está licenciado sob forma de uma licença Creative Commons Atribuição 4.0 Internacional.
Resumo: Diferentemente dos aspectos mais propriamente culturais que subjazem a colonização rural teuto-brasileira dos séculos XIX e XX, os temas agrários e florestais permanecem estritamente localizados nas realidades ambientais e sociais do Brasil meridional. Vige como um discurso duradouro a impressão de que as práticas e conhecimentos agrícolas e silvestres dos colonizadores florestais teuto-brasileiros tivessem como origem as imposições da dimensão americana do processo migratório; logo, a ideia de ruptura dos sistemas agrários e de uso florestal se impôs sem maiores contestações. Neste artigo, objetivamos repensar estas suposições através do recurso ao conceito de transferências, embebido em uma roupagem de história ambiental e sob uma perspectiva particular da história do conhecimento, os conhecimentos de migrantes. Observa-se, assim, que o nascimento da agricultura florestal e ignea teuto-brasileira também esteve associado aos saberes e práticas do mundo camponês alemão. Três vetores de transferência são com mais detalhes analisados: em primeiro lugar, o exercício de uma agricultura extensiva, carente de insumos de pecuária; segundamente, o recurso ao fogo como instrumento de conversão florestal e fertilização; e, por fim, a adoção de cultivares nativos pelas populações rurais teuto-brasileiras. Esses fluxos especificos permitem afirmar a mobilidade e conexão de conhecimentos e práticas silvestres e agrícolas entre Brasil e Alemanha. Assim, antes de ser um evento especificamente americano, a agricultura teuto-brasileira se revestiu de intensos hibridismos, marcados por fenômenos de transferência.

Palavras-chave: Agricultura. Floresta. Colonização alemã. Transferência. Conhecimento.

Abstract: Differently from the more cultural aspects that underlay German-Brazilian rural colonization in the $19^{\text {th }}$ and $20^{\text {th }}$ centuries, agrarian and silvan themes remain strictly placed in the social and environmental realities of southern Brazil. This discourse is still up to date and it reinforces the assumption that agricultural-silvan practices and knowledge carried by German-Brazilian rural society had their origins solely on the impositions of the south American side of the migration. Thus, the idea of rupture regarding agrarian systems and forest use imposed itself without further countercharges. In this paper, we aim at rethinking these assumptions through the concept of transfer, embedded into an environmental history approach and under a perspective of the history of knowledge, or better said, migrant knowledge. We claim that the birth of the German-Brazilian igneous and forest agriculture had been associated to the previous knowledge and practices of the German peasantry. Three vectors of transfers will be then analyzed: firstly, the management of extensive agriculture deprived from enough inputs of husbandry; second, the use of fire as a tool for land clearance and manuring; finally, the adoption of native crops by German-Brazilian rural society. These specific flows allow to argue the mobility and connections of knowledge and agricultural-silvan practices between Germany and Brazil. Therefore, before being an exclusively south American development, German-Brazilian agriculture was distinguished by hybridism, marked by transfer phenomena.

Keywords: Agriculture. Forest. German colonization. Transfers. Knowledge.

\footnotetext{
1 Universidade do Vale do Rio dos Sinos (Unisinos), São Leopoldo, RS, Brasil.
} 
Resumen: Diferentemente de los aspectos más propiamente culturales que subyacen la colonización rural alemana-brasileña de los siglos XIX y XX, los temas agrarios y forestales permanecen estrictamente ubicados en las realidades ambientales y sociales del Brasil meridional. Ese discurso se queda aún actual y refuerza la impresión de que las prácticas y conocimientos agricolas y silvestres de los colonizadores forestales alemán-brasileños tuviesen su origen solamente en las imposiciones de la dimensión americana del proceso de migración. Así, la idea de ruptura de los sistemas agrarios y de los usos de los bosques se impuso sin mayores contestaciones. En este artículo, objetivamos repensar esas suposiciones a través del recurso al concepto de transferencia, envuelto en una perspectiva de historia ambiental y bajo una dimensión particular de la historia del conocimiento, los conocimientos de los migrantes. Observa-se asimismo que el nacimiento de la agricultura forestal y ígnea germano-brasileña estuve asociado a los saberes y practicas del mundo campesino alemán. Tres vectores de transferencia son con más detalles analizados: primero, el ejercicio de la agricultura extensiva, carente de insumos de la ganaderia; segundamente, el recurso al fuego como instrumento de conversión forestal y fertilización; y, por fin, la adopción de cultivos agrícolas nativas por la sociedad germano-brasileña. Eses flujos específicos permiten afirmar la movilidad y conexión de los conocimientos y practicas silvestres-agricolas entre Brasily Alemania. Por lo tanto, antes de ser un evento especificamente americano, la agricultura alemana-brasileña se caracterizó por intensos hibridismos, marcados por fenómenos de transferencia.

Palabras clave: Agricultura. Bosque. Colonización alemana. Transferencia. Conocimiento.

\section{Introdução}

Os deslocamentos migratórios interoceânicos do século XIX ocasionaram toda a sorte de dramas pessoais e familiares. Dificuldades surgiam imediatamente após o baixar das âncoras e por muito tempo elas acompanhariam os neófitos em seus novos lares. Lingua, clima, costumes, todos esses eram elementos de estranhamento e anunciavam a necessidade de aprendizados fundamentais e dolorosos

No caso da imigração rural do Brasil meridional, não menos importantes do que os aspectos acima citados foram os temas levantados pelos manejos agricolas e florestais implementados. Os migrantes que se assentaram na Mata Atlântica sulina a partir do primeiro quartel do século XIX eram majoritariamente agricultores, cultivadores de hortas ou empregados rurais. A migração exigiu a predisposição à flexibilidade, adaptação e transferência de seus conhecimentos laborais. Ao cruzarem fronteiras, os migrantes alemães traziam consigo agriculturas e florestas.

Atores e atrizes de práticas e saberes agroflorestais foram os colonos e colonas teutobrasileiros que, em razão da própria natureza do processo migratório, administraram conhecimentos sob condições de mobilidade. O reconhecimento de tal condição nos aproxima do objetivo central deste artigo, que se fundamenta em repensar a noção de ruptura dos sistemas agrários e florestais entre Alemanha e Brasil e, desse modo, reposicionar essas questões em torno de um eixo de transferências e conexões translocais.

A percepção do paradigma da ruptura agrícola-florestal foi e continua sendo bastante disseminada nas mais diversas especialidades e acompanha os discursos sobre a colonização rural no sul do Brasil de modo generalizado; diferentemente dos aspectos mais propriamente culturais do processo de migração germânica como a religião, a língua, a escolarização, as identidades étnicas etc., as práticas agrícolas e silvestres surgem como elementos não passiveis de conexões. Ademais, os manejos empreendidos pelos colonizadores germânicos nas florestas brasileiras teriam, para muitos, significado a prova cabal de um processo de "aculturação" pelo abrasileiramento (WILLEMS, 1946, p. 228-230). Logo, para pensarmos uma história conectada da agricultura e da floresta entre Brasil e Alemanha, de modo que a impressão de ruptura seja evitada e uma aproximação entre mundos possa ser esboçada, teremos de entendê-las, ambas, como constructos culturais; agricultura e exploração silvestre são atravessadas por conhecimentos de diversas ordens e são por isso também cultura, podendo, justamente por esse motivo, serem comunicadas, reelaboradas, incorporadas e traduzidas às práxis e repertórios dos agentes (MCNEILL; MAULDIN, 2012, p. XVI).

Os vetores de transferência relativos aos conhecimentos silvestres e agricolas surgem, assim, como ferramentas centrais de obtenção de competências transculturais (HOERDER, 2009, p. 247), pois do controle desses saberes dependeu boa parte do êxito dos migrantes em seus novos destinos.

Neste texto abordaremos precisamente a 
migração de populações falantes de línguas alemãs para o Brasil meridional durante o século XIX. Nesta macrorregião brasileira, estabeleceramse desde 1824, homens, mulheres e crianças oriundos de diferentes Estados alemães, que se dedicaram majoritariamente ao cultivo de lotes de terra em colônias agricolas. Essas pessoas imprimiram suas experiências nas paisagens e foram pontes humanas de globalização, estabelecendo fluxos e estreitando distâncias culturais e ambientais entre diferentes espaços (HOERDER, 2012, p. 76).

Do ponto de vista conceitual, este artigo dialoga com uma agenda em global environmental history e history of knowledge; através da ênfase na noção de transfer aplicada ao problema das histórias agricolas e florestais, ela aborda, de modo especial, a circulação de saberes postos em marcha pelo fenômeno das migrações em massa do século XIX. Os temas da economia dos conhecimentos, vêm sendo, no caso da recente e vigorosa historiografia em história global, ainda largamente ignorados (FISCHER, 2017, p. 280); as pesquisas sobre transferências culturais, da mesma forma, praticamente não incidem sobre temas agrários e continuam sólidas em torno das descrições das migrações intelectuais entre unidades subnacionais previamente definidas (KAELBLE, 2009, p. 33-34). Além disso, no que concerne ao trânsito de saberes em condições de mobilidade, migrantes e colonizadores são surpreendentemente negligenciados em prol de narrativas voltadas aos numericamente limitados - mas nem por isso menos importantes - experts e scholars. Por trás dessa direção, a alegada tradição programática da história do conhecimento como sinônimo de história da ciência; assim, cumpre delimitar este texto como um exercício de "migrant knowledge" (LÄSSIG, 2016, p. 36).

Feita esta pequena digressão, passaremos logo a discorrer sobre os temas propostos. Em primeiro lugar, rumaremos para as condições de agricultura e floresta nas Alemanhas ${ }^{2}$, particularmente na
Prússia do século XIX; segundamente, apontaremos os mesmos temas, mas perspectivando o lado brasileiro em seu quadrante meridional; e, por último, situaremos os processos de mediação, negociação e transferência existentes entre os dois espaços supracitados sob o esforço de conclusão dos argumentos.

\section{Floresta e agricultura na Alemanha- Prússia: breves considerações}

$\mathrm{Na}$ época das primeiras migrações para o Brasil, na já longinqua década de 1820, os camponeses alemães experimentavam significativas mudanças em suas relações com a terra arável e florestal. Não obstante, novos e velhos processos se imiscuiam e formavam no meio rural uma verdadeira e irresistivel era de transição. Reflexos da história agrária do século XVIII - profundamente identificados com as realidades do Antigo Regime - dialogavam com as inovações técnicas, jurídicas e sociais advindas da recepção e desenvolvimento do iluminismo e liberalismo nas Alemanhas (BÜSCHER, 1997, p. 11-14).

A fome era, porém, ainda parte integrante do ciclo agrícola e poucas gerações podiam naquela época se orgulhar de não terem passado por privações dessa natureza (MONTANARI, 1995, p. 155-156). Ainda em 1817, poucos anos após o fim das Guerras Napoleônicas, a Europa central fora atingida pelas cinzas do vulcão indonésio Tambora (a erupção ocorreu em 1816), que causou - em pleno estio europeu - uma arrasadora quebra de safra nas lavouras de batata e de cereais (HERRES; HOLTZ, 2011, p. 131). A fome de 1817 - embora causada por um fator excepcional - e a conflagração europeia interromperam um processo de bonança agricola que se espalhava pelo continente desde a última crise das colheitas de 1771-1774, revelando a circularidade dos problemas que afetavam o mundo da agricultura e a continuidade de eventos de "type ancien" em pleno século XIX (RÖSENER, 1993, p. 187). 
Do ponto de vista das mudanças na agricultura e nas formas de exploração florestal, três elementos estruturais podem ser destacados. Em primeiro lugar, o processo conhecido na Alemanha como Bauernbefreiung ${ }^{3}$; em sequência, a revolução tecnológica da agricultura de fins do século XVIII e que se arrastou por todo o século XIX; e, por último, o paulatino controle material e epistemológico das florestas alemãs por um corpo de funcionários públicos burocratizados, especializados e treinados cientificamente: a Forstwirtschaft ou engenharia florestal. Entre os estados alemães, a Prússia se notabilizou por conduzir esta agenda reformadora da sociedade rural, mas, de nenhuma maneira, monopolizou tais iniciativas, seja no âmbito da Europa alemã, seja no panorama maior do continente europeu (BRAKENSIEK, 2006, p. 40-42). A ênfase na Prússia decorre também do fato de que foi ela a maior expulsora de emigrantes para o Brasil.

Em comparação com a Inglaterra e a França, a liberação camponesa prussiana seguiu um modelo intermediário de reformas agrárias. $\mathrm{Na}$ França, tal processo fora marcado pelos arroubos da Revolução iniciada em 1789; na Inglaterra, o individualismo agrário ocorreu por uma via marcadamente econômica, ligada ao processo de protoindustrialização e industrialização que o pais sofreu entre os séculos XVII e XVIII. No reino dos Hohenzollern, a liberação dos camponeses e o processo de dissolução da servidão foi marcado pela tutela estatal sob forte institucionalização. Em 1807, o Edito de Outubro - outorgado em uma Prússia humilhada militarmente pela França napoleônica - proclamou a liberdade corporal e de movimento dos servos sem maiores indenizações à ordem senhorial (KOSELLECK, 1989, p. 488489). O Edito de Regulação de 1811 e o seu complemento de 1816 terminaram por administrar as compensações havidas entre os direitos e os deveres de nobres e servos, já que ambas as partes fechavam uma espécie de contrato de servidão baseado no uso da terra e alocação de força de trabalho; se o Edito de 1807 tratou da liberdade do corpo camponês (liberdade de casamento, profissão, fim do serviço doméstico obrigatório na casa do nobre ou Gutsherr etc.), o Edito de 1811 e o seu complemento de $1816 \mathrm{se}$ reportaram à equalização da liberdade econômica e fundiária dos camponeses e nobres prussianos sob o prisma dos antigos direitos e deveres do vínculo servil. Para que o camponês tivesse a propriedade de seu solo, algumas compensações eram necessárias de ambos os lados; elas envolviam somas em dinheiro e, na falta desse, era facultado ao mesmo a cessão de metade ou de um quarto de sua terra de trabalho para o Juncker, de modo a que ambos desfrutassem de seus lotes sob a égide da propriedade privada plena e desembaraçada. Além disso, os Editos de 1811 e de 1816 visaram regular e quantificar as relações advindas da Konservation, espécie de seguro senhorial prestado ao servo para o caso de necessidades gerais e má sorte nas colheitas. Nem todos os camponeses eram aptos a regular as suas propriedades sob esses dois instrumentos; a regulação do vinculo servil dependia outrossim de condições especificas ligadas à hereditariedade da posse da terra, do tamanho da propriedade e, por último, do acordo concreto de servidão estabelecido pelos agricultores e/ou seus ascendentes e nobres em tempos passados (EDDIE, 2013, p. 65-67).

Em 1821, a Ablösungsordnung ou ordenação para compensações fora passada na Prússia de modo que mais camponeses pudessem se habilitar a reformarem o status das terras que trabalhavam. Desta vez, agricultores que tinham direitos de posse mais estabelecidos e que desfrutavam de uma condição de dependência com o nobre baseada em Grundherrschaft ${ }^{4}$ puderam regular as suas terras de modo satisfatório (SCHNEIDER, 2010, p. 135-38). Através dessas disposições, a maioria dos camponeses prussianos teve condições de regular a posse e a propriedade de suas terras.

Também chamado liberação camponesa ou individualismo agrário.

Grundherrschaft dizia respeito a um conceito de propriedade de solo que não incluía o que se produzia acima dele, tampouco o que se achava em seu subsolo. Ele está ligado ao principio latino de dominium directum e tal instituto marcou a paisagem fundiária do oeste da Alemanha (WARDE, 2010, p. 39). 
Detentores de pequenas parcelas, entretanto, não lograram por sua vez regular seus lotes agricolas e permaneceram sob o estatuto feudal até a Revolução de 1848. Esses indivíduos formavam quase sempre as camadas inferiores da comunidade aldeã da Prússia e, não raro, estavam sujeitos aos gravames das crises agricolas; foram eles também que, frequentemente, engrossaram as fileiras da emigração para países distantes e alimentaram a questão coletiva do Pauperismus (NIPPERDEY, 1994, p. 172).

Complementar e contemporânea ao processo de liberação camponesa e de constituição de uma economia rural de ordem liberal-burguesa nas Alemanhas, foram as alterações tecnológicas na agricultura. Esse movimento foi chamado na Europa de "primeira revolução agrícola dos tempos modernos" e se caracterizou, sobretudo, pela renúncia ao pousio ou alqueive (MAZOYER; ROUDART, 2010, p. 353-354). De novo, estaremos mais atentos ao que aconteceu na Prússia.

Ainda no século XVIII, comissários e altos funcionários pertencentes grosso modo à tradição cameralista dos Estados mercantilistas alemães se debruçaram sobre o problema da agricultura e se lançaram em soluções para o aumento da eficácia produtiva no campo. 0 impulso pelo progresso agrícola era de fato um tema europeu transnacionalizado, na medida que a Fisiocracia se estabeleceu como uma escola econômica de primeira importância no continente, englobando agentes e conhecimentos de modo supraterritorial (HOBSBAWN, 2006, p. 323-325). Ademais, a recepção da obra de Thomas Malthus tornou ainda mais urgente o impulso por investimentos na produtividade agricola face ao imperativo demográfico dos estudos malthusianos (SCHNEIDER, 2010, p. 7).

Em relação à revolução agrícola nas AlemanhasPrússia dos séculos XVIII e XIX, destacamos a substituição do modelo de três campos (Dreifeldwirtschaft) pelo sistema de rotação de culturas (Fruchtfolge). As consequências dessa virada tecnológica podem ser exemplificadas pelos seguintes movimentos: a introdução maciça da batata tanto para consumo humano quanto animal; o cultivo do trevo (Klee), batata e beterraba nas áreas outrora destinadas ao pousio do sistema de três campos; a pressão gradativa pelo término das obrigações comunitárias incidentes sobre o cultivo obrigatório de determinadas parcelas nos territórios agrícolas das aldeias (Flurzwang); a estabulização dos rebanhos (principalmente bovino e suíno) e o melhor aproveitamento do estrume animal para fins de adubação; a crescente separação dos manejos agrícolas e florestais; e, como consequência direta dos dois últimos aspectos, o fim paulatino das áreas comunais (Allmende) de produção agropecuária, fato esse acompanhado pelo processo de liberação camponesa (GUDERMANN, 2001, p. 47).

Todos esses acontecimentos foram inovações relevantes para se entender os aumentos de produtividade na agricultura, bem como, por consequência, as dificuldades surgidas para os camponeses dos extratos empobrecidos, pois esses eram mais dependentes dos recursos comunais preexistentes, a exemplo de florestas, prados e charnecas (HÖLZL, 2010, p. 489). Com efeito, a adoção da rotação de culturas implicou em um aumento da capacidade de custeio das safras e as pressões de capital sobre os camponeses alavancaram e fortificaram antigas diferenças sociais no contexto da sociedade aldeã (CATT, 1986, p. 144-145). As mudanças na agricultura são de fato tão profundas nests periodo que Frank Uekötter (2005, p. 141-147) ousou sublinhar que o intervalo temporal entre 1750 e 1850 se constituiu em um "turning point" na história da agropecuária global, haja vista a radicalização e a profundidade das mudanças observadas.

Na Prússia, o debate agricola permeava as conversas nos grandes escalões governamentais. Em 1756, o rei Frederico II, o Grande (17121786), decretou o Edito da Batata de Potsdam (Kartoffeledikt von Potsdam), ordenando a população camponesa a plantar batata e a se familiarizar com seu cultivo (DIEPENBROCK; ELLMER; LEON, 2016, p. 35). No campo das ciências agrárias, Albrecht Thaer (1821, p. 219220), considerado o fundador da agronomia alemã e membro do Conselho do Ministério do 
Interior prussiano, além de professor na recéminaugurada universidade berlinense, afirmava em seu livro Grundsätze der rationellen Landwirtschaft a necessidade do melhoramento do solo por meio de adubação intensiva; ele defendia outrossim o término do pousio característico do sistema de três campos através do plantio de culturas próprias para o consumo animal. Ademais, o sistema de rotação de culturas deveria igualmente funcionar integrado ao processo de estabulização (THAER, 1821, p. 235). O ocaso do sistema de três campos, uma conquista da Baixa Idade Média baseada em escolhas técnicas e padrões de assentamento característicos, conduziu a uma reorganização do espaço rural das Alemanhas. Por conseguinte, a reconfiguração da produção agrícola se operou de forma lenta através do século XIX e não pode ser separada das demais rupturas que ocorreriam simultaneamente.

Desta forma, a agricultura dos campesinos (ländliche Gesellschaft) cedeu espaço a uma agricultura de orientação burguesa (landwirtschaftliche Gesellschaft), bastante intensiva em energia e capital, que se solidificou na Alemanha após a fundação do Kaiserreich (UEKÖTTER, 2010, p. 45). Enquanto a primeira foi um espaço de socialização - embora não idílico e imerso em conflitos internos -, relativamente destinada para a subsistência, baseada em insumos locais e, via de regra, comunalmente administrada, a segunda operava de modo transversal e se caracterizava pela intromissão de outros atores até então estranhos à vida rural (engenheiros florestais, agrônomos, engenheiros mecânicos, empresas de automação agrícola, indústrias de insumos, etc.). A landwirtschaftliche Gesellschaft não estava, além disso, mais presa à localidade dos insumos agrícolas e diante dela abria-se o mercado mundial do guano, do salitre e dos hidrocarbonetos fósseis. A agricultura moderna-burguesa foi, por outro lado, responsável por afastar definitivamente as catástrofes da fome e da penúria do campo alemão, mas também criou problemas ambientais de duradoura repercussão, desigualdades e hierarquias intransponiveis, forçando milhões de pequenos possuidores de terra (Häusler, Kossaten, Büdner etc.) e jornaleiros rurais (Tagelohner) aos desesperos da emigração ou aos cortiços das cidades alemãs em vias de industrialização. Todavia, a agricultura burguesa triunfou em produtividade, garantiu os estoques alimentares de uma sociedade que se industrializava rapidamente e assegurou uma existência material cômoda para milhares de outros agricultores bem posicionados nas pirâmides sociais de suas aldeias (BAUER, 2009, p. 416-417).

Mudanças nas relações sociais e na forma de produzir causaram alterações adicionais nas paisagens e nos aproveitamentos que os camponeses faziam usualmente de suas florestas. Uma terceira ruptura no mundo camponês ocorreu com a introdução da engenharia florestal (Forstwirtschaft) no manejo silvestre das comunidades rurais.

A floresta era a maior usina energética do periodo pré-industrial. Ela era o elemento central e estruturante de toda vida econômica até a incorporação maciça e pioneira do carvão mineral nos mais diferentes processos produtivos. Para Paul Warde, "wood was the raw material that permitted early modern life" (WARDE, 2006, p. 39). A retórica conclusiva do pesquisador inglês, altamente categórica, não deve ser por isso negligenciada.

Na passagem do século XVIII para o século XIX, a engenharia florestal ganhou autonomia e legitimidade discursiva. Nascida da necessidade de os pequenos Estados alemães garantirem fontes fiscais seguras - com destaques para as atividades de mineração, metalurgia e exploração madeireira -, a engenharia florestal deu ao mundo através do saxão Hans Carl von Carlowitz (16451714) em sua obra Sylvicultura Oeconomica (1713) a ideia de sustentabilidade ou Nachhaltigkeit. Esse é por vezes considerado o momento fundador da engenharia florestal, pois ali já se expressavam os esboços de uma ciência organizada, epistemologicamente centrada, empiricamente definida e, sobretudo, integrada aos organismos de Estado (WILLIAMS, 2003, p. 206). Ademais, através de Nachhaltigkeit preconizava-se a adoção de critérios de racionalidade para a 
exploração e planejamento de florestas de modo que a previsibilidade dos ganhos financeiros com a floresta fosse aferida através de critérios matemáticos, estatísticos e biológicos. Mais importante do que isso, Nachhaltigkeit era igualmente um princípio de ordenação futura, haja vista que o critério norteador da ciência florestal era justamente a constante renovação dos recursos florestais. A engenharia florestal prometia a eternidade das matas, embora não garantisse a biodiversidade, o acesso ampliado aos recursos e a diversidade de usos.

O discurso científico dos engenheiros florestais, surgido nas academias mantidas e equipadas pelos príncipes alemães ainda no século XVIII, atacava, sobretudo, o relacionamento entre o camponês e a floresta por ele explorada (KÜSTER, 2013, p. 185). A tutela florestal estatal nas Alemanhas fora uma invenção do século XVI e desde sempre se constituiu em um instrumento de poder e state building nas mãos dos príncipes germânicos (RADKAU; DUNLAP, 2008, p. 138). Mas foi somente entre os séculos XVIII e XIX que a Forstwirtschaft se tornou um braço influente e atuante do Estado; mais do que isso: engenheiros e guardas florestais eram, por vezes, os únicos agentes estatais que travavam contato direto com uma extensa população camponesa (WARDE, 2010, p. 221). Em termos gerais, o objetivo estatal era a produção continuada e sustentável de biomassa florestal para fornecimento dos parques protoindustriais e industriais existentes no interior das potestades políticas. A madeira também era um produto de altíssimo valor comercial e redes de comércio internacionais funcionavam e atingiam grande parte dos centros florestais da Alemanha como, por exemplo, o comércio madeireiro através do rio Reno, ligando a Floresta Negra, o Hunsrück, o Eifel e o Palatinado aos centros maritimos e comerciais da Holanda (CIOC, 2002, p. 63). Ademais, o comércio madeireiro extrapolava as fronteiras europeias; desde 1844, por exemplo, a Prússia exportava madeiras do Memel para o Rio de Janeiro sob condições alfandegárias bastante proveitosas, estipuladas pelo acordo comercial bilateral "Freundschafts-, Schiffahrts- und Handelsvertrag vom 9. Juli 1827" (PENKWITT, 1983, p. 79).

A floresta para o camponês das Alemanhas era, sobretudo, um recurso agrícola. Ela não era obviamente um espaço de concretização de políticas mercantilistas, ainda que muitas comunidades rurais participassem com maior ou menor vigor dos circuitos comerciais madeireiros e agrícolas. Porém, antes de tudo, a floresta camponesa era um espaço misto de agricultura, pecuária e extrativismo tacitamente designada como Landwirtschaftswald ou floresta agricola (ERNST, 2000, p. 19). Além disso, era um território de cobertura das necessidades vitais básicas, incluindo aquecimento doméstico, alimentação e construção (LEHMANN, 2010, p. 10).

Em primeiro lugar, era na sombra das árvores que os gados bovino, equino e suíno pastavam com regularidade e sazonalidade. Ao consumirem os recursos florestais e as novas mudas que brotavam das clareiras, bem como sementes, frutos e bolotas das espécies arbóreas que as produziam, os animais não somente se alimentavam para produzir os produtos de pecuária que deles eram esperados, como também produziam estrume; esse era reintroduzido no ciclo agricola, alimentando a produtividade dos cultivos. $O$ estrume animal produzido nos ambientes florestais era muito valorizado como fertilizante, em razão de nele se misturarem outros produtos em decomposição no solo da floresta. A serrapilheira misturada ao esterco animal era reconduzida aos campos e servia como complemento de fertilização do solo nas culturas cerealiferas que, via de regra, configuravam os cultivos de subsistência (HACHENBERG; HÜTTE; LÖBER, 1992, p. 74-88).

Folhas eram também retiradas de algumas árvores para complementarem a nutrição dos rebanhos; as folhas secas, que formavam a liteira do solo da floresta, eram extraídas de modo a se produzir um substituto para a palha e, com isso, manter os animais relativamente limpos e confortáveis termicamente. A apicultura era igualmente um importante atributo da floresta e era largamente realizada em espécies arbóreas que produziam determinados tipos de flores. Por 
fim, a coleta de frutos silvestres e cogumelos complementava a dieta de muitas familias camponesas (SCHMIDT, 2010, p. 23-42).

Praticava-se, inclusive, agricultura dentro da floresta (Waldfeldbau) nas AlemanhasPrússia. A floresta camponesa fora de fato uma espécie de mata média (Mittelwald) e mata baixa (Niederwald), originada justamente do uso - por vezes abusivo - pastoril e agricola desse território pela população rural (SCHMIDT, 2002, p. 5). Em territórios prussianos que a partir de 1824 foram protagonistas da emigração para o Brasil (o Eifel e o Hunsrück, exemplarmente), essas práticas eram relativamente comuns. Os manejos conhecidos como Schiffelwirtschaft ou Rotteckenwirtschaft, Haubergwirtschaft, Reutbergwirtschaft, entre outros, combinavam agricultura de centeio, aveia, trigo sarraceno (Buchweizen) e batatas, extração da casca do carvalho para curtimento de couros, uso da madeira dos carvalhos e faias para carvoaria e pastoreio animal nas áreas desmatadas; todas essas atividades eram combinadas com o uso do fogo, que proporcionava através da combustão de gravetos, folhas e alguns troncos de árvores, a cinza necessária para a adubação e a calagem das culturas agrícolas acima descritas (MANTEL; HAUFF, 1990, p. 89-106). Tais métodos eram caracterizadores de populações carentes e empobrecidas, que não dispunham de quantidades suficientes de estrume e, por isso, desempenhavam práticas agrícolas extensivas.

O uso da floresta nas Alemanhas dependia também das vocações protoindustriais e industriais dos diferentes estados e regiões. No leste da Alemanha, na região do Harz e da Saxônia, vigoravam até metade do século XIX diferentes empreendimentos ligados à mineração de ferro e prata, bem como indústrias de vidros, sabões e curtumes que demandavam um grande fornecimento energético e matérias-primas oriundas das florestas. Destaca-se nesse sentido a extração de potassa, subproduto da queima da faia e cujas cinzas eram hidratadas de modo a se obter uma pasta para ser usada tanto na indústria de sabões quanto nos processos de fundição de vidros; ademais, a potassa era também utilizada por inúmeras comunidades rurais das AlemanhasPrússia como fertilizante nas plantações de cereais (STEINSIEK; LAUFER, 2012, p. 190).

Por fim, cremos que a extração de potassa e os manejos igneos nas Alemanhas mereçam ser mais profundamente considerados por historiadores da imigração alemã ao Brasil, do meio ambiente e da agricultura; pois esses elementos prometem esclarecer uma série de mediações vivenciadas pelos imigrantes alemães no processo de aprendizado agrícola e florestal na América do Sul. Pensamos haver nesse sentido um ponto de aproximação entre a agricultura subtropical brasileira e a agricultura da Europa central, haja vista que o uso do fogo para fins agricolas era igual e largamente praticado nas regiões de expulsão dos imigrantes alemães, principalmente no leste das Alemanhas. Ademais, e sob um nivel ainda mais fundamental, os usos agrícolas e multifuncionais das florestas do mundo camponês germânico estavam intimamente associados às florestas caducifólias temperadas que, através de aguda decidualidade, geravam recursos aos agricultores.

\section{Floresta e agricultura teuto-brasileira: considerações e transferências}

Elemento recorrente em cartas, diários, memórias, literatura e outros tipos de documentos, as florestas do Brasil meridional (bioma Mata Atlântica) foram também protagonistas do processo de imigração alemã. No seio da mata virgem ou do Urwald5, os teuto-brasileiros construíram as suas roças, igrejas, casas e famílias.

A história da instalação da agricultura teutobrasileira e do desmatamento têm sido contada de diferentes maneiras. Chama atenção, entretanto, na literatura memorialista/municipalista e em algumas análises socioeconômicas da imigração alemã, o fato de tais processos - agricultura e desmatamento - serem percebidos como automáticos e necessários; nessa linha de interpretação, os processos ecológicos desempenham papel nulo ou acanhado.

\footnotetext{
5 Termo utilizado nas comunidades teuto-brasileiras para designar as florestas do Brasil meridional.
} 
Por outro lado, a inserção transversal do environmental turn nas ciências humanas e sociais produziu uma radicalização do discurso ambientalista no interior do scholarship que, por sua vez, embora ainda bastante restrito, respingou nas interpretações do processo de manejo agroflorestal efetivado pelos teutobrasileiros. Historiadores ambientais realçaram os aspectos ecológicos da colonização alemã do Brasil meridional, mas teceram, anacronicamente, críticas descontextualizadas ao estabelecimento dos assentamentos em suas relações com o mundo natural. Essa postura ignora tanto as condições materiais de construção das colônias no Urwald, as culturas agrárias dos povos alemães em movimento, quanto à envergadura da destruição ambiental da Mata Atlântica. Predominou nesse discurso historiográfico uma narrativa inexorável da destruição, que constitui, por sua vez, uma tradição da recepção latino-americana à história ambiental (CAREY, 2009, p. 222).

Estes dois extremos - o colono-pioneiro-herói e o colono-perturbador da natureza - empobrecem e dificultam a compreensão da instalação da agricultura teuto-brasileira. Preferimos, assim, a abordagem sensivel de Joao Klug (2010, p. 308) ao afirmar que, antes de qualquer coisa, os teuto-brasileiros tiveram de aprender a se tornar colonos do Urwald. O autor argumenta que os colonos foram aprendizes de uma natureza nova e agiram no sentido de avaliar - graças aos seus conhecimentos agronômicos obtidos na Europa central e também por toda uma sorte de literatura (NEUMANN, 2005, p. 258), além de contatos com lavradores nacionais, diretores de colônia e afins (ALVIM, 1997, 272) - as melhores e possiveis estratégias que pudessem surtir os efeitos desejados em termos de produção agrícola. Nem sempre houve sucesso; o fracasso de algumas experiências, para Klug, se tornou também parte integrante da construção da agricultura teuto-brasileira.

Saindo dos principios que informam a narrativa historiográfica da agricultura, da pecuária e da exploração florestal efetivada pelas comunidades teuto-brasileiras, entramos, portanto, no mundo das conexões, rupturas e dos transfers. Existem três grandes temas que podem ser assim explorados: em primeiro lugar, a separação entre a pecuária e a agricultura nas colônias do Urwald; em segundo lugar, e em conexão com o primeiro, o uso do fogo na agricultura e na conversão de área florestal em área arável; e, por fim, a adoção de cultivos nativos pelos teuto-brasileiros.

Leo Waibel (1958, p. 302-307), após realizar pesquisa de campo nas outrora recentes fronteiras agricolas-florestais teuto-brasileiras, alertava em 1958 que os colonos necessitavam integrar finalmente a pecuária à agricultura, pois percebia entre os mesmos uma verdadeira e definitiva "adubofobia". O geógrafo alemão tomou como referência antigos manejos agrícolas da Europa central, que consorciavam pastoreio na floresta e intensificação da adubação nos campos e os comparou com a realidade florestal teutobrasileira. Waibel acreditava que a Mata Atlântica era usada como suporte de adubação (combustão de biomassa), pois apontava um problema crônico de exiguidade de rebanhos para produção de estrume. A queima da floresta pelo sistema de roça (Roçawirtschaft e Capoeirawirtschaft) causava o rápido esgotamento do solo e gerava novos deslocamentos da comunidade teutobrasileira pelo território brasileiro e, até mesmo, para outros países (Paraguai, Argentina e Bolivia, principalmente). Logo, Leo Waibel acreditava em uma regressão técnica da lavoura teuto-brasileira, pois essa teria abandonado a pecuária, elemento fundamental da revolução agrícola do Neolítico.

Günter Weimer (1988, p. 112) afirmava que a menor severidade do inverno no Brasil fez com que a floresta perdesse a sua centralidade na agropecuária dos colonos. Weimer calculou que, em média, as áreas cobertas por florestas no interior de um lote teuto-brasileiro convencional não ultrapassavam os 10\% da área total da propriedade, provocando mudanças no manejo da pecuária. Elas se referiam à menor necessidade de estabulização e, consequentemente, à menor disposição de estrume, além do reduzido impulso em manter áreas florestais de maior extensão com o intuito de captação de lenha para aquecimento doméstico. 
Não há, tampouco, análises mais detalhadas sobre as razões da desintegração inicial entre pecuária e agricultura nas colônias teutobrasileiras. De qualquer modo, o que se revela tanto na historiografia quanto nas estruturas dos saberes agronômicos dos teuto-brasileiros é o fato de que a floresta no Brasil foi concebida dentro da ideia de fertilização e adubação do solo. A biomassa florestal teria substituido os insumos da pecuária, pois esses eram relativamente caros para uma população francamente descapitalizada e em processo de assentamento no ambiente florestal, onde predominava terreno arborizado e diminutas áreas vazias. Além disso, as ameaças dos animais selvagens (felinos, principalmente), muitos deles amplamente desconhecidos pelos neófitos, rondavam os rebanhos.

Há, de alguma forma, desde o século XIX, breves elucubrações econômicas sobre o fenômeno. O viajante saxão Woldemar Schultz (1865, p. 39), reverberando a teoria de intensividade/ extensividade de Johann Heinrich von Thunen ${ }^{6}$ no Brasil meridional e baseado no exemplo da expansão agrícola da colônia Santa Cruz em fins da década de 1850, acreditava que a distância aos mercados, a exiguidade de animais domésticos, a ausência de pastagens e os altos salários cobrados na rarefeita fronteira agricola teriam, por fim, conduzido os colonos ao fogo florestal.

Como matéria de hipótese, a menor aplicação de insumos de pecuária na agricultura teutobrasileira pode estar inter-relacionada com aspectos, ao mesmo tempo, econômicos e culturais; como vimos anteriormente, os migrantes alemães - principalmente aqueles originados da Prússia Renana, Palatinado Bávaro, Baden e Nassau - dispunham de um sedimentado repertório agronômico para enfrentar os desafios de uma agricultura descapitalizada e praticada em áreas remotas. O fogo também ali compensou a ausência de estrume e se configurou como uma medida para otimizar trabalho humano. Do lado brasileiro, deve-se cogitar o papel do latifúndio na limitação dos rebanhos na economia rural cabocla, haja vista as condições inseguras de posse da terra e a violência das relações sociais (WISSENBACH, 1997, p. 49-52); logo, aspectos brasileiros podem ter igualmente contribuído para tais fenômenos observados entre os alemães.

Carência de animais domésticos, uma cultura agronômica de espaços extensivos, oferta elástica de terras novas e colonos descapitalizados foram os ingredientes do fogo teuto-brasileiro. Mas antes, há um interessante ponto a ser considerado. Ele diz respeito aos tipos de florestas encontradas na Mata Atlântica do sul do Brasil. O Urwald precisava também ser adaptável à agricultura itinerante dos alemães.

Nesse sentido, Eunice Nodari (2012, p. 35) distingue os conceitos agrários-florestais teutobrasileiros de "mata branca" e "mata preta". A "mata branca" seria para os colonos um tipo de floresta com presença diminuta de coniferas, ou no caso sul-brasileiro, uma floresta sem araucárias (Araucaria angustifolia). Inversamente, a "mata preta" responderia a uma associação com áreas concentradas de araucária, onde o único fenômeno brasileiro de monodominância florestal ocorre. A "mata branca" seria mais própria ao uso agrícola (Roçawirtschaft), ao passo que a "mata preta" corresponderia à silvicultura. Não por acaso, o pinheiro de araucária ou pinheirobrasileiro foi o carro chefe do estabelecimento do Brasil nos circuitos madeireiros globais a partir da Primeira Guerra Mundial (CARVALHO, 2015, p. 327).

Nodari distinguiu esse conhecimento silvestre teuto-brasileiro através de fontes históricas variadas e entrevistas com agricultores descendentes de imigrantes alemães. Mas a autora não avançou na perspectiva transcultural desse saber. Porque tal distinção - "mata branca" e "mata preta" - remonta aos conhecimentos florestais e agronômicos oriundos da Europa central, haja vista que nas Alemanhas os camponeses ordenavam as florestas a partir da predominância de gimnospermas (Nadelholzwald), angiospermas

\footnotetext{
6 Economista agrário e agrônomo (1783-1850) nascido no Principado de Anhalt-Zerbst. Argumentava a inviabilidade da agricultura comercial e intensiva longe de centros urbanos consumidores, dada a ausência de redes de transportes adequadas. Em: VON THUNEN Johann Heinrich. Der isolierte Staat in Beziehung auf Landwirtschaft und Nationalökonomie. Rostock: Leopold, 1842. p. 1-3
} 
(Laubwald) ou florestas mistas (Mischwald). Neste sentido, as matas agropecuárias (Landwirtschaftswald) eram majoritariamente as florestas temperadas deciduas (Laubwald); já as florestas de coniferas eram espaços associados à produção madeireira (Holzwirtschaftswald). As florestas mistas atendiam de alguma forma ambos os interesses. O fundamental nessa distinção é o fato de que Laubwald7 se reporta ao processo fenológico de produção e queda das folhas das árvores; essas e as sementes do carvalho, da faia, das castanhas e demais frutos eram intensamente usadas pelas populações rurais na lide dos rebanhos e na satisfação de demandas de subsistência. A Nadelholzwald nem produzia sementes, tampouco folhas coletáveis, fatores que dificultavam o uso agricola desse espaço (SCHMIDT, 2002, p. 198-199). A própria eficácia dos sistemas de manejo ígneo como Rottwirtschaft. Haubergwirtschaft e outros afins demandava o uso de florestas do tipo Laubwald, pois ali tanto a faia quanto o carvalho eram as espécies arbóreas preferidas para a fertilização do solo; a decidualidade de suas folhas gerava húmus em quantidades apreciáveis, além de biomassa na liteira para combustão. A Landwirtschaftswald era, sobretudo, uma floresta multifuncional.

Sob esse corpo de saberes, as florestas estacionais deciduais e semideciduais do sul do Brasil se traduziram nas florestas agrícolas dos imigrantes alemães. Elas eram a "mata branca" aludida por Nodari. As florestas estacionais são afetadas pelo inverno mais rigoroso do Brasil meridional e esse fato obriga muitas espécies arbóreas à reserva energética. Ao perderem boa parte de suas folhas - a decidualidade no Brasil era, no entanto, bem mais reduzida do que nas Alemanhas - elas geravam insumos e recursos aos agricultores especializados em cultivos extensivos. Logo, os imigrantes transportaram, através de fenômenos de transferência que, obviamente, precisaram ser reatualizados, enriquecidos e traduzidos, ora em uma perspectiva intragrupo, ora em uma dimensão de contato com a sociedade brasileira, as agriculturas e os usos silvestres de suas terras de origem.

O próprio fogo cruzou fronteiras e se estabeleceu no Brasil meridional como um possivel fenômeno de transferência. Ele se tornou o principal instrumento de fertilização do solo e o seu uso foi intensificado no Brasil em comparação às comunidades rurais alemãs. No entanto, nas Alemanhas do século XIX existiam diferentes manejos agrícolas que usavam o fogo como instrumento técnico. Assim, por exemplo, baseados nos relatos de Johann Nepomuk Hubert von Schwerz (1831, p. 13-14), amigo e colaborador intelectual de Albrecht Thaer, camponeses do Hunsrück e Eifel - regiões pertencentes à Prússia renana e hotspots de emigração ao sul do Brasil - encontravam-se inteiramente familiarizados com os efeitos do fogo e das cinzas na produtividade da agricultura. Além disso, a difundida utilização da potassa no sudoeste das Alemanhas conectava a queima de biomassa florestal com maiores produtividades do solo, realidade observada in loco por Lothar Müller (1906, p. 147) e corroborada através das estatísticas do distrito de Simmern (Hunsrück). Sob essa lógica, as brasileiras Roçawirtschaft e Capoeirawirtschaft se tornaram capítulos adicionais do relacionamento entre agricultores da Europa central e o fogo, a despeito do desprezo eurocêntrico e colonial de historiadores, geógrafos, agrônomos e antropólogos europeus acerca da história ígnea do velho continente (SIGAUT, 1979, p. 679-680).

Como as coniferas em geral são mais resistentes aos efeitos da aplicação do fogo (GOLDAMMER, 1993, p. 95), os camponeses alemães preferiam as florestas de carvalho e faia para fazer agropecuária. Haubergwirtschaft e outros manejos semelhantes localizados ao longo do Reno, eram preferencialmente conduzidos em florestas desses tipos, administradas e conduzidas, geralmente, por meio de Niederwald (baixa floresta, cortada e manejada periodicamente). Nas Alemanhas do 
século XIX existiam as seguintes nomenclaturas para designar diferentes técnicas de aplicação do fogo silvestre e agricola: Hackwaldwirtschaft, Reutberge e Reutfelder na Alemanha meridional e paises alpinos; Haubergwirtschaft na região de Siegerland (provincia Westphalen, Prússia); Rottbüsche e Schiffeländereien, na margem esquerda do Reno (Hunsrück e Eifel, Rheinprovinz, Prússia); Röderwaldwirtschaft e Röderlandbetriebe, na Pomerânia (Prússia), Odenwald (Grão-ducado de Baden), Áustria, Bélgica e França setentrional; Birkenberge na Baviera; Laßräume na Prússia oriental; Laßwiesen e Röder na Saxônia; e Zinswiesen na Silésia (Prússia) (GOLDAMMER, 1997, p. 18). Especialmente interessante ao pesquisador da imigração alemã para o Brasil são os manejos ocorridos na margem esquerda do Reno e na Pomerânia, pois ambas as regiões, pelo menos no que se refere ao sul do Brasil, foram preponderantes no envio de colonizadores.

Em relação aos cultivos agricolas mais comuns entre os teuto-brasileiros, esses foram marcadamente tropicais e demarcaram, por isso, territórios de alteridade no interior dos conhecimentos agronômicos postos em movimento. Mandioca, milho, abóbora, batata, cana-de-açúcar e feijão; essas eram as culturas agricolas e os alimentos que subiam à mesa dos colonos e que igualmente se transformaram em vetores de agricultura comercial. Com especial destaque neste último sentido, se inclui o tabaco, largamente plantado na próspera colônia alemã de Santa Cruz no Rio Grande do Sul (VOGT, 1997. 69-72). Muitos imigrantes, porém, transportaram sementes e mudas para o Brasil de forma a replicar seu cabedal agronômico no além-mar (ALVES, 2003, p. 180). Mas o sucesso de determinadas plantas dependia consideravelmente do solo, climas, conhecimentos acumulados, trocas com a população local e, não menos importante, dos próprios mercados consumidores. No geral, os cultivos de horta permaneceram europeus e as culturas propriamente agricolas se reportaram ao conjunto das plantas tropicais-latinoamericanas.

A história da agricultura teuto-brasileira costuma ser descrita como uma história de rupturas, e isto é ainda mais visivel quando lembramos das culturas que, de fato, foram preferidas pelos agricultores germânicos do Brasil meridional. Do ponto de vista da pecuária e criação, observamos, todavia, conexões mais acentuadas; o desenvolvimento da suinocultura e de uma pujante indústria de laticinios atestaram as mobilidades das vocações produtivas entre as Alemanhas e o Brasil.

Muito embora os teuto-brasileiros tivessem que aprender uma nova agricultura e dominar os padrões nativos de cultivo - o relato do colonizador boêmio Josef Uman (1997, p. 64) no Rio Grande do Sul oitocentista é, neste sentido, contundente -, algumas das culturas típicas da agricultura tropicalbrasileira já eram plantadas nos campos europeus do século XIX e mesmo em periodos ainda mais recuados. Ainda que se tratassem de variantes, o milho fora introduzido nas Alemanhas no século XVIII e já no começo do século XIX popularizaramse receitas com base nesse grão pelos campos alemães, principalmente nas regiões mais cálidas da bacia do Reno (KÖRBER-GROHNE, 2001, p. 89-93). O tabaco já era amplamente cultivado na Prússia do século XVIII (EDDIE, 2013, p. 131). Os feijões sulamericanos chegaram na Europa ainda no século XVII e o cultivo de leguminosas era uma realidade estabelecida na Europa central desde pelo menos o século X da era cristã (ALBALA, 2007, p. 41). Batatas foram introduzidas nas Alemanhas por volta de fins do século XVI, mas a produção agrícola ganhou impulso e um caráter de massa somente a partir do século XVIII (MESSER, 2000, p. 190-193); originária dos Andes, os alemães foram ironicamente os responsáveis pela reamericanização do tubérculo a partir das precoces migrações para o sul do Brasil no século XIX.

\section{Considerações finais: transfers na agricultura e floresta teuto-brasileira}

A história florestal e agricola brasileira, de Gilberto Freyre (2011, p. 76-77), passando por Sergio Buarque de Holanda (2007, p. 66-67), Leo Waibel (1958, p. 302), até pelos contemporâneos historiadores ambientais, é marcada pela onipresente noção de ruptura. A ruptura dos padrões ibéricos e, no caso da colonização 
germânica, a quebra dos padrões da agricultura e da exploração florestal da Europa central perfazem o discurso das scholarships correspondentes. Não é, entretanto, o objetivo deste trabalho negar certas descontinuidades ocorridas entre esses espaços, mas, principalmente, no que se refere à imigração alemã para o Brasil no século XIX, de relativizá-la e pô-la em contexto de comunicação e de estabelecimento de fluxos e de transferências.

Logo, percebemos que as grandes migrações do século XIX não somente transportaram pessoas, mas levaram, de um lado a outro do oceano, ideias, conhecimentos e experiências que se multiplicaram e que influenciaram mutuamente os territórios atingidos. Além disso, a partir de 1880, a Alemanha unificada adquiriu status de potência colonial; circulavam por todo o mundo de língua alemã - inclusive nas zonas teuto-brasileiras rurais e demais cidades do Brasil - publicações e relatos sobre outras florestas e agriculturas tropicais e subtropicais, que se estendiam das Américas até a Oceania (KUNDRUS, 2003, p. 311). Os agentes desses processos foram múltiplos. Desde migrantes e suas experiências de vida, até editores, empresas colonizadoras, publicistas, religiosos etc. Esses atores diversos, donos de múltiplos projetos, não se confundem única e exclusivamente com os interesses dos estados envolvidos nas migrações. E é neste sentido, que gostariamos de falar das transferências agrárias e florestais.

A noção de tranfer surgiu na esteira da insatisfação de muitos historiadores com o paradigma do nacionalismo metodológico e com a insuficiência das histórias globais em tocar as vivências dos atores em niveis mais localizados (FREITAG; OPEN, 2010, p. 7). Ademais, é necessária a imaginação de uma outra ideia de região ou localidade. Essas vêm sendo recentemente concebidas como espaços dinâmicos de construção e de prática social expostos a diferentes ritmos de definição, seguindo desenvolvimentos conceituais do spatial turn. Desta forma, a região e a localidade existiriam em termos de um perpétuo jogo de formação e dissolução de fronteiras; e tal processo ocorre dentro de órbitas que extrapolam movimentos meramente localizados. Neste sentido, o historiador pode incorporar ao seu vocabulário metodológico ideias como fluxos, transições e transferências. Em vez de imaginar unidades territoriais estáticas (uma colônia no Brasil meridional, uma cidade alemã, uma zona ecológica etc.), ele pode as imaginar em termos de vetores, que não se restringem às fronteiras dos Estados e que são movidas por atores de diferentes condições (EPPLE, 2013, p. 24).

Na historiografia de imigração alemã ao Brasil meridional é mais comum perceber impetos globalizantes nas narrativas que se dedicam às histórias da cultura. Língua, religião, arquitetura, escolarização, todos esses são temas que comportam para mais ou para menos aspectos de conexão entre as sociedades das Alemanhas e as sociedades teuto-brasileiras. Logo, pensamos que a marginalização dos temas da agricultura e da floresta, neste sentido, precisa ser superada.

As florestas do Brasil meridional devem ser compreendidas, na esteira do pensamento de Regina Horta Duarte (2005, p. 45), como paisagens hibridas e não somente como um imperativo ecossistêmico independente do domínio humano. A floresta não é só feita de raizes, flores, folhas, animais e demais processos ecológicos aferiveis pela biologia e ciências naturais em geral; os discursos que as fundamentaram também construiram a realidade e, com frequência, incorporaram questões de gênero, científicas, conhecimentos especializados e tácitos. Esses discursos possuem, por sua vez, um alcance maior do que supõe a mera extensão fisica da floresta; pois essa não se acaba na última árvore antes do campo. As florestas se conectam a uma rede de informações que geram transferências capazes de determinar futuras configurações socioambientais, com influências diretas nos sistemas agrários.

Logo, a floresta teuto-brasileira, ou o Urwald, é também uma construção das agriculturas e dos usos silvestres europeus. O justo reconhecimento da necessidade do teuto-brasileiro em aprender agricultura e conhecer a Mata Atlântica meridional através dos lavradores nacionais talvez não 
baste per se para entendermos os processos de transferência ocorridos. Fazer uma história somente e exclusivamente brasileira desse processo, a partir da ideia da ruptura definitiva, parece não ser mais suficiente. Acreditamos, portanto, que seja necessário incluir a história agrária e florestal das regiões de origem dos colonizadores em nossas análises para assim avaliarmos melhor as soluções tomadas pelos agentes em questão. Desta forma, uma história de transfers entre Brasil, Alemanhas e outros espaços pode ser extremamente útil para uma melhor caracterização dos processos, saberes e conhecimentos que animaram a agricultura e o manejo florestal no sul do Brasil.

\section{Referências}

ALBALA, K. Beans: a History. London: Bloomsbury Publishing PLC, 2007. https://doi. org/10.5040/9781350025677

ALVES, Débora B. Cartas de imigrantes como fonte para o historiador: Rio de Janeiro-Turingia (18521853). Revista Brasileira de História, São Paulo, v. 23, n. 45, p. 155-184, 2003. https://doi.org/10.1590/ S0102-01882003000100007

ALVIM, Zuleika. Imigrantes: a vida privada dos pobres do campo. In: NOVAIS, Fernando (org.). História da vida privada no Brasil: República: da belle époque à era do rádio. São Paulo: Cia das Letras, 1997. p. 215-287.

BAUER, Alfred. Ländliche Gesellschaft und Agrarwirtschaft im Hunsrück zwischen Tradition und Innovation (1870-1914). Trier: Kliomedia, 2009.

BRAKENSIEK, Stefan. Reformas agrarias y transformación de la sociedad rural en el siglo XIX. In: VARELA, Jesús M. G; LAFUENTE, G. S. (org.). Sociedades agrarias y formas de vida: La historia agraria en la historiografia alemana, siglos XVIII-XX. Zaragoza: Prensas Universitarias de Zaragoza, 2006. p. 27-46.

BÜSCHER, Karl. Entstehung und Entwicklung des landwirtschaftlichen Bildungswesens in Deutschland. Münster-Hiltrup: Landwirtschaftsverl, 1997.

CAREY, Mark. Latin American environmental history: current trends, interdisciplinary insights, and future directions. Environmental History, Oxford, v. 14, n. 2, p. 221-252, 2009. https://doi.org/10.1093/ envhis/14.2.221

CARVALHO, Ely B. Problematizando as representações do mundo natural como delimitação espacial em História Ambiental: Entre a Araucarilândia e a Floresta Ombrófila Mista. Revista de História Regional, Ponta Grossa, v. 20, n. 2, p. 317-342, 2015. https:// doi.org/10.5212/Rev.Hist.Reg.v.20i2.0006
CATT, Cathlenn S. Farmers and factory workers: Rural society in Imperial Germany: the example of Maudach. In: EVANS, R. J.; LEE, W. R. (org.). The German peasantry: conflict and community in rural society from the eighteenth to the twentieth centuries. London: Croom Helm, 1986. p. 129-157.

ClOC, Mark. The Rhine: an eco-biography, 1815-2000. Washington D.C: Univ. of Washington Press, 2002.

DIEPENBROCK, Wulf; Ellmer, Frank; Léon, Jens. Ackerbau, Pflanzenbau und Pflanzenzüchtung: Grundwissen Bachelor. Stuttgart: UTB GmbH, 2016.

DUARTE, Regina Horta. História \& natureza. Belo Horizonte: Autêntica, 2005.

EDDIE, Sean A. Freedom's price: Serfdom, subjection, and reform in Prussia, 1648-1848. Oxford: Oxford University Press, 2013.

EPPLE, Angelika. Lokalität und die Dimensionen des Globalen: Eine Frage der Relationen. In: BRAHM, F.; EPPLE, A.; HABERMAS, R. (org.). Thema: Lokalität und transnationale Verflechtungen. Böhlau: Wien, Köln, 2013. p. $4-25$

ERNST, Cristoph. Den Wald entwickeln. München: Oldenbourg, 2000.

FISCHER, Georg. Globalisierte Geologie: Eine Wissensgeschichte des Eisenerzes in Brasilien (1876 - 1914). Frankfurt (am Main); New York: Campus, 2017.

FREITAG, Ulrike; VON Oppen, Achim. Introduction: 'Translocality': an approach to connection and transfer in Area Studies. In: FREITAG, Ulrike; VON OPPEN, Achim (org.). Translocality: The study of globalising processes from a southern perspective. Leiden, Boston: Brill, 2010. p. 1-24.

FREYRE, Gilberto. Casa-grande \& senzala: formação da familia brasileira sobre o regime da economia patriarcal. São Paulo: Global, 2011.

GOLDAMMER, Johann Georg. Feuer in Waldökosystemen der Tropen und Subtropen. Basel, Boston: Birkhäuser, 1993.

GOLDAMMER, Johann Georg; Montag, Susanne; Page, Hans. Nutzung des Feuers in mittel- und nordeuropäischen Landschaften Geschichte, Methoden, Probleme, Perspektiven. In: Alfred Toepfer Akademie für Naturschütz, Schneverdingen, v. 10, n. 5, p. 18-38, 1997.

GUDERMANN, Rita. Der take-off der Landwirtschaft im 19. Jahrhundert und seine Konsequenzen für Umwelt und Gesellschaft. In: DITT, Karl; GUDERMANN, Rita; RÜSSE, Norwich (org.). Agrarmodernisierung und ökologische Folgen: Westfalen vom 18. bis zum 20. Jahrhundert. Paderborn: Schöningh, 2001. p. $47-84$.

HACHENBERG, Friedrich; HÜTTE, Paul; LÖBER, Ulrich 2000 Jahre Waldwirtschaft am Mittelrhein: Begleitpublikation zur gleichnamigen Ausstellung des Landesmuseums Koblenz und der Bezirksregierung Koblenz-Forstdirektion. Koblenz: Landesmuseum, 1992. 
HERRES, Jürgen; Holtz, Bärbel. Rheinland und Westphalen als preußische Provinzen (1814-1888). In: MÖLICH, Georg; VELTZKE, Veit; WALTER, Bernd. (org.) Rheinland, Westfalen und Preußen: eine Beziehungsgeschichte. Münster: Aschendorff, 2011. p. 113-208.

HOBSBAWN, Eric J. A era das revoluções: 1789-1948. Rio de Janeiro: Paz e Terra, 2006.

HOERDER, Dirk: Losing National Identity or Gaining Transcultural Competence. In: HAUPT, Heinz-Gerhardt; KOCKA, Jürgen (org.). Comparative and Transnational History: Central European Approaches and New Perspectives. New York, Oxford: Bergbahn Books, 2009. p. 247-271.

HOERDER, Dirk. Transnational - transregional - translocal: transcultural. In: VARGAS-SILVA, C. (org.). Handbook of Research Methods in Migration. Cheltenham, UK: Edward Elgar, 2012. p. 69-91.

HOLANDA, Sérgio B. Raizes do Brasil. São Paulo: Companhia das Letras, 2007.

HÖLZL, Richard. Umkämpfte Wälder: Die Geschichte einer ökologischen Reform in Deutschland 1760-1860. Frankfurt am Main/New York: Campus Verlag, 2010.

KAELBLE, Hartmut. Between Comparison and Transfers - and What Now? a French-German debate. In: HAUPT, Heinz-Gerhard; KOCKA, Jürgen (org.). Comparative and Transnational History: Central European Approaches and New Perspectives. New York, Oxford: Bergbahn 2009. p. 33-38.

KÖRBER-GROHNE, Udelgard. Nutzpflanzen in Deutschland: Von der Vorgeschichte bis heute; das kompetente Nachschlagewerk. Hamburg: Nikol, 2001.

KOSELLECK, Reinhart. Preußen zwischen Reform und Revolution: Allgemeines Landrecht, Verwaltung und soziale Bewegung von 1791 bis 1848. München: Klett-Cotta, 1989.

KLUG, Joao. Imigração alemã, agricultura e meio ambiente no sul do Brasil no início do século XX. In: MUGGE, Miquéias H.; MUGGE, Erny; MUGGE; HAEUNSTEIN, Iria (org.). Construindo diálogos: história, educação e ecumenismo. São Leopoldo: Oikos, 2010. p. 301-312.

KUNDRUS, Birgit. Moderne Imperialisten: Das Kaiserreich im Spiegel seiner Kolonien. Köln: Böhlau, 2003

KÜSTER, Hansjörg. Geschichte des Waldes: Von der Urzeit bis zur Gegenwart. München: Beck, 2013.

LÄSSIG, Simone. The history of knowledge and the expansion of the historical research agenda. Bulletin of the GHI, Washington, v. 56, Fall, p. 29-58, 2016.

LEHMANN, Albert. Der deutsche Wald: Kulturmuster und Identitätsymbol. In: DEPENHEUER, Otto; MÖHRING, Bernhard (org.). Waldeigentum: Dimensionen und Perspektiven. Berlin-Heidelberg: Springer Verlag, 2010. p. 3-19. https://doi.org/10.1007/978-3-642-00232-8_1

MAZOYER, Marcel; ROUDART, Laurence. História das agriculturas no mundo: Do neolítico à crise contemporânea. São Paulo, Brasilia: Ed. UNESP; NEAD, 2009, 2010.
MESSER, Ellen. Potatoes (White). In: KIPLE, Kenneth F.; ORNELAS, Kriemhild Coneè (org.). The Cambridge world history of food. Cambridge, UK; New York: Cambridge University Press, 2000. p. 187-201. https://doi.org/10.1017/CHOL9780521402149.023

MIECK, Ilja. Preußen und Westeuropa. In: NEUGEBAUER, Wolfgang (org.). Handbuch der preussischen Geschichte: Das 17. und 18. Jahrhundert und große Themen der Geschichte Preußens. Berlin [u.a.]: De Gruyter, 2009. p. 411-853.

MONTANARI, Massimo. Der Hunger und der Überfluß: Kulturgeschichte der Ernährung in Europa. München: Beck, 1995.

NEUMANN, Gerson Roberto. Brasilien ist nicht weit von hier!: die Thematik der deutschen Auswanderung nach Brasilien in der deutschen Literatur im 19. Jahrhundert (1800 - 1871). Frankfurt am Main: Lang, 2005.

NODARI, Eunice Soeli. "Mata branca": o uso do machado, do fogo e da motoserra na alteração da paisagem no Estado de Santa Catarina. In: NODARI, Eunice Soeli; KLUG, Joao (org.). História ambiental e migrações. São Leopoldo: Oikos, 2012. p. 35-53.

MCNEILL, John; MAULDIN, Erin S. Global Environmental History: an Introduction. In: McNEILL, John; MAULDIN, Erin S. (org.). A companion to global environmental history. Malden: Mass, 2012. p. 16-24 https://doi.org/10.1002/9781118279519

MÜLLER, Lothar. Die Landwirtschaft auf dem Hunsrück: unter besonderen Berücksichtigung der des Kreises Simmern. Bonn: Carl Georgi, 1906.

NIPPERDEY, Thomas. Deutsche Geschichte 1800-1866: Bürgerwelt und starker Staat. München: Beck, 1994.

PENKWITT, Wolfgang. Preussen und Brasilien: Zum Aufbau des preussischen Konsularwesens im unabhängigen Kaiserreich (1822-1850). Wiesbaden: Kommission bei F. Steiner, 1983.

RADKAU, Joachim; DUNLAP, Thomas. Nature and power: A global history of the environment. Washington D.C. Cambridge, New York: German Historical Institute; Cambridge University Press, 2008.

RÖSENER, Werner. Die Bauern in der europäischen Geschichte. München: Beck, 1993. https://doi. org/10.7788/gik.1994.35.1.153

SCHMIDT, Uwe E. Der Wald in Deutschland im 18. und 19. Jahrhundert: das Problem der Ressourcenknappheit dargestellt am Beispiel der Waldressourcenknappheit in Deutschland im 18. und 19. Jahrhundert: eine historisch-politische Analyse. Saarbrücken: Conte-Verl., 2002.

SCHMIDT, Uwe E. Geschichte des Waldeigentums und der Forstwirtschaft. In: DEPENHEUER, Otto; MÖHRING, Berhard (org.). Waldeigentum: Dimensionen und Perspektiven. Berlin-Heidelberg, Springer Verlag, 2010. p. 23-42.

SCHNEIDER, Karl H. Geschichte der Bauernbefreiung. Stuttgart: Reclam, 2010. 
SCHULTZ, Woldemar. Studien über agrarische und physikalische Verhältnisse in Südbrasilien: In Hinblick auf die Kolonisation und freie Einwanderung. Leipzig: Ernst Julius Günther, 1865

SCHULZE, Frederik. A constituição global da nação brasileira: questões de imigração nos anos 1930 e 1940. História, Ciências, Saúde: Manguinhos, Rio de Janeiro, v. 21, n. 1, p. 237-246, 2014.

SIGAUT, François. Swidden cultivation in Europe: A question for tropical anthropologists. Social Science Information, v. 18, n. 4-5, p. 679-694, 1979. https://doi. org/10.1177/053901847901800403

STEINSIEK, P. M.; LAUFER, J. Quellen zur Umweltgeschichte in Niedersachsen vom 18. bis zum 20. Jahrhundert: Ein thematischer Wegweiser durch die Bestände des Niedersächsischen Landesarchivs. Göttingen: Vandenhoeck \& Ruprech, 2012

THAER, Albrecht. Grundsätze der rationellen Landwirthschaft. Berlin: Reimer, 1821.

UEKÖTTER, Frank. Turning points in environmental history. German Historical Institut, Washington D.C. v. 37. fall, p. 141-147, 2005

UEKÖTTER, Frank. Die Wahrheit ist auf dem Feld: eine Wissensgeschichte der deutschen Landwirtschaft. Göttingen: Vandenhoeck \& Ruprecht, 2010.

UMAN, Josef. Memórias de um imigrante boêmio. Porto Alegre: EST/Nova Dimensão, 1997.

VOGT, Olgário Paulo. A produção de fumo em Santa Cruz do Sul, RS, 1849-1993. Santa Cruz do Sul: EDUNISC, 1997

VON SCHWERZ, Johann Nepomuk Hubert. Beiträge zur Kenntnis der Landwirtschaft in den Gebirgsgegenden des Hunsrücken. Möglischen Annalen der Landwirtschaft, v. 27, p. 1-62, 1831.

VON THUNEN, Johann Heinrich. Der isolierte Staat in Beziehung auf Landwirtschaft und Nationalökonomie. Rostock: Leopold, 1842.

WAIBEL, Leo. Princípios da colonização europeia no sul do brasil. Revista Brasileira de Geografia, Rio de Janeiro, v. 11, n. 2, p. 159-222, 1949

WAIBEL, Leo. Capitulos de geografia tropical e do Brasil. Rio de Janeiro: IBGE Serviço Gráfico, 1958.

WARDE, Paul. Fear of wood shortage and the reality of the woodland in Europe, c. 1450 - 1850. History workshop journal, Oxford, v. 62, n. 3, p. 28-57, 2006.

WARDE, Paul. Ecology, economy and state formation in early modern Germany. Cambridge: Cambridge Univ. Press, 2010

WEIMER, Gunther. Hunsrücker in Süd-Brasilien oder: wo ist das deutsche Dorf geblieben? Landeskundliche Vierteljahrsblätter, Trier, v. 34, p. 109-118, 1988.

WILLEMS, Emilio. A aculturação dos alemães no Brasil: Estudo antropológico dos imigrantes alemães e seus descendentes no Brasil. São Paulo: Comp. Ed. Nacional, 1946.
WILLIAMS, Michael. Deforesting the earth. Chicago: University of Chicago Press, 2003

WISSENBACH, Maria C. Cortez. Da escravidão à liberdade: dimensões de uma privacidade possivel. In: NOVAIS, Fernando (org.). História da vida privada no Brasil; República: da belle époque à era do rádio. São Paulo: Cia das Letras, 1997. p. 49-130.

\section{Eduardo Relly}

Doutor em História pela Universidade Livre de Berlim (FU Berlin); bolsista PNPD-Capes na Universidade do Vale do Rio dos Sinos (Unisinos), São Leopoldo, RS, Brasil.

\section{Endereço para correspondência}

Eduardo Relly

Rua Caramuru 21, apto 602

92010-160

Canoas, RS, Brasil 